\title{
Translation of the 'Landscape Architecture' Into Chinese and How to Build the Discipline of Landscape Architecture in China?
}

\author{
Heyi Wei (Corresponding author) \\ Geodesign Research Centre, Jiangxi Normal University \\ Ziyang Road No. 99, Nanchang 330022, China \\ E-mail: weihy@whu.edu.cn
}

Wenhua Jiang

Geodesign Research Centre, Jiangxi Normal University

Ziyang Road No. 99, Nanchang 330022, China

E-mail: w.jiang@jxnu.edu.cn

Received: December 24, 2019 Accepted: February 2, 2020 Published: February 4, 2020

doi: $10.5296 /$ ire.v8i1.16381

URL: https://doi.org/10.5296/ire.v8i1.16381

\begin{abstract}
The translation and connotation of landscape architecture (LA) caused a lot of controversy in academia when the term 'LA' was introduced to China. In this study, we summarized the different opinions of Chinese scholars based on the origin, evolution, and professional contents of LA, which can be divided into 'Jing Guan Jian Zhu' (Chinese Pinyin), 'Jing Guan She Ji', and 'Feng Jing Yuan Lin'. Finally, this article provides strategies and suggestions for enhancing the development of LA when the first-level discipline is established in China, and the aim is to narrow the gap with the international community.
\end{abstract}

Keywords: Terms translation, Discipline construction, Differences, Chinese landscape architecture

\section{Introduction}

The International Federation of Landscape Architects (IFLA) and American Society of 
Landscape Architects (ASLA) are professional associations, which are generally recognized by international landscape architects in the world. The term of 'Landscape' is very popular in academia with the exchange and integration of Eastern and Western, but so far no consensus has been reached in China. The landscape architecture is a generic term for the most of scholars in Europe and North America, however, there are a lot of vocabulary corresponding to it in China, such as 'Zao Yuan', 'Jing Guan Jian Zhu', 'Feng Jing Jian Zhu', 'Yuan Lin Jian Zhu', 'Feng Jing Yuan Lin', and 'Yuan Lin'(Wang, 1999). As a result, they caused some confusion and difficulties in connecting the international community. In order to solve this problem, we conducted an extensive literature search based on the CNKI (China National Knowledge Infrastructure), Google Scholar, and other academic search engines. The purpose of this study is to make it clear, which kind of translation for the LA is more appropriate in China. And how to promote the development of LA in China, especially after the establishment of the first-level discipline in 2011.

\section{How to Translate the Landscape Architecture Into Chinese?}

\subsection{LA Is the Jing Guan Jian Zhu?}

The term of 'Jing Guan Jian Zhu' was first quoted by Taiwanese scholar Jichang Wang in 1969, when he translated John Ormsbee Simonds' book, 'Landscape Architecture: A manual of environmental planning and design'. Therefore, 'Jing Guan Jian Zhu' is the first time to appear in Chinese literature in 1969.

The LA was enlightened in the UK and developed in the America. American landscape architecture is greatly influenced by the United Kingdom, especially the natural landscape gardens of the UK from the 18th to the 19th century. In the traditional British terminology, the landscape gardening and landscape gardener are still widely used at present ( $\mathrm{Li} \&$ Qin, 1994; Wang, 1999). In the America, the LA was originally positioned to develop urban park and open green spaces, and used to serve urban citizens. In 1857, the Central Park was established in Manhattan, New York City, which plays a very important role in the leisure, recreation and relaxation of the citizens. Because of this, the two designers, Frederick Law Olmsted and Calvert Vaux, are called landscape architects.

Most scholars believe that the LA is an important branch of Architecture, and is the result of crosscutting and integration with planning, gardening and ecological geography, especially who are architectural backgrounds. At the same time, it is believed that landscape architecture realizes the perfect harmony between humans, architecture, and nature (Lin, 2003). How to determine the connotation, attribution and division of LA? We believe that different scholars have different understandings. Such as Liuqiang Jia and Jian Qiu, they think LA is not a branch of Architecture, the role of LA is to scientifically allocate land and buildings for human habitation, living and entertainment. They also believe that "Jiang Guan Jian Zhu, architecture and urban planning are three parallel disciplines" (Jia \& Qiu, 2008). From this we can see that the LA is translated into 'Jing Guan Jian Zhu', which is accepted by some Chinese scholars. 
2.2 LA Is the Jing Guan She Ji?

The introduction of 'Jing Guan She Ji' was on April 13, 2003, and the first graduate school was established for landscape architecture at the Yanyuan Lake of Peking University. As a dean, Kongjian Yu translated LA into 'Jing Guan She Ji', and explained its complete connotation and extension. The results caused some controversy and criticism, especially among some traditional Chinese scholars of 'Feng Jing Yuan Lin' (Liu et al., 2004). In addition, Kongjian Yu brought the keynote report, and named "The art of survival: position landscape architecture" at the IFLA held in May 2006 and the ASLA annual meeting in October, which caused great influence in the international community ( $\mathrm{Li}, 2007)$. The agricultural society of China has experienced thousands of years, and land occupies an important position in the hearts of the people. However, the contradiction between people and land is extremely prominent with the rapid increase in population. How to coordinate the contradiction between people and land, to plan the landscape elements in a scientifically and rationally way, thereby reducing the input of material and energy as much as possible, and maximize the ecological benefits, cultural functions and artistic value. 'Jing Guan She Ji' is the art of survival and can solve these problems today.

LA is a science and art, which is about how to arrange land and spaces on land, to create a safe, efficient, healthy and comfortable environment (Yu \& Liu, 1999). In addition, LA is a profession that solves all the problems of human use of land and outdoor space, the direction includes landscape design and landscape planning (Yu, 2004). It can be seen, Kongjian $\mathrm{Yu}$ believes that Chinese 'Jing Guan She Ji' is more appropriate corresponding to English LA based on the literatures and the practical work of landscape architects. Compared with Chinese 'Feng Jing Yuan Lin', LA can better reflect the close relationship between humans and nature, and solve the real problems of contemporary China. The core role of LA is to resolve the crisis of the relationship between humans and land resources with the development of urbanization and industrialization. As he advocated, LA pursues the harmony of Nature, Humans and God (Zhang, 2007).

\subsection{LA Is the Feng Jing Yuan Lin?}

Chinese traditional gardens have been recorded for more than 3,000 years. With the development of the times, there are many types of garden have emerged. Such as royal gardens, private gardens, temple gardens, public gardens, scenic spots, and so on (Liu, 2005). From the historical perspective of development, the stakeholders served by the garden have changed a lot. The service object from dignitaries in feudal society to ordinary citizens, and to humans in today. Therefore, how to translate LA into Chinese? 'Feng Jing Yuan Lin' is the LA? Senior gardening experts suggest that LA should be translated into 'Feng Jing Yuan Lin' in China. Jiale Li (2002) believes that the world's population has grown exponentially, and how to develop natural resources in an orderly manner is an urgent problem to be solved, especially under the premise that human beings live in harmony with nature. Thereby, he suggested that the scope of the gardening discipline should be expanded to the field of landscape planning. That is, 'Feng Jing Yuan Lin' consists of four branches, named landscape gardening, landscape horticulture, urban gardening, and earthscape planning, respectively ( $\mathrm{Li}$, 
2002).

What is the connotation of 'Feng Jing Yuan Lin'? Xiaoxiang Sun (2002) believes that 'Feng Jing Yuan Lin' mainly plays two roles in China, one is to protect and plan scenic spots at the national or local level, and to provide planning for nature reserves, national forests, grasslands, wetlands, rivers and lakes, seashores, islands, etc. second, 'Feng Jing Yuan Lin' can provide planning and maintenance for the urban green space system, such as for urban street greening, residential area greening, urban parks, country parks, tourist and leisure places, resort planning, and so on (Sun, 2002). From the explanation of Xiaoxiang Sun, we can see that 'Feng Jing Yuan Lin' plays the dual task of nature protection, and artificial landscape planning. What is the LA? ASLA gives a specific vision in the official website, that is "landscape architects analyze, plan, design, manage, and nurture the built and natural environments. Landscape architects have a significant impact on communities and quality of life. They design parks, campuses, streetscapes, trails, plazas, and other projects that help define a community" (ASLA 2018). Therefore, we can conclude that the work of landscape architects in North America is very close to the current idea from Xiaoxiang Sun. However, there is still a certain gap between 'Feng Jing Yuan Lin' and LA in the range of occupations and disciplines connotation at present.

\section{Several Key Issues for the Construction of LA Discipline}

In March 2011, the Ministry of Education of China promulgated the 'Catalogue of Degrees and Talents Training'(2011). It is clearly stated that 'Landscape Architecture' has become a first-level discipline and will no longer be attached to 'Architecture', 'Forestry' or 'Urban Planning'. It can be awarded a degree in engineering or a degree in agronomy. Most scholars believe that this will play a positive role in promoting the future cultivation of talents and career development of landscape architecture in China (Chen, 2011; Zhang, 2011). It can be seen that the recognition of society for landscape architecture has raised greater expectations and social responsibilities for Chinese LA discipline. We can't be overconfident that 'Feng Jing Yuan Lin' in China is the international LA, and 'Feng Ling Yuan Lin' is an all-encompassing discipline system. Therefore, we believe that 'Feng Jing Yuan Lin' should accept new theories to meet the needs of new practice areas in the future. To this end, we propose some ideas and suggestions to promote the development of LA in China and to fill the gap with the international community.

\subsection{Curriculum Design of LA}

The courses in LA at universities in China can be generally divided into public courses, professional basic courses, professional courses, experiment courses and practical courses (Table 1). It can be seen from the curriculum system, the knowledge, technology and skills of LA students that trained during college can't fully meet the requirements of LA in practices. With the rapid development of urbanization in China, the contradiction between economic development and ecological protection is more prominent. To this end, the ecological philosophy should be added to the curriculum system of LA. The role of this course is to give landscape architects a clear picture of where people are in the environment, and how to deal with the relationship between people, land and space. In order to support the planning and 
management of large-scale natural resources and landscape, some technology platforms should also be used as one of LA course, such as geographic information systems (GISs) technology. In addition, some courses can be reduced, adjusted or cancelled, which are not conducive to the development of comprehensive abilities for students.

Table 1. Curriculum system of LA at university in China

\begin{tabular}{|c|c|c|c|c|}
\hline Types & Class names & $\begin{array}{l}\text { Credit } \\
\text { scores }\end{array}$ & $\begin{array}{l}\text { Number of } \\
\text { classes }\end{array}$ & Semester \\
\hline \multirow[t]{12}{*}{$\begin{array}{l}\text { Public } \\
\text { course }\end{array}$} & $\begin{array}{l}\text { Ideological and Moral Cultivation } \\
\text { and Legal Basis }\end{array}$ & 3 & 48 & 1 \\
\hline & $\begin{array}{l}\text { Outline of Modern and Contemporary } \\
\text { Chinese History }\end{array}$ & 2 & 32 & 2 \\
\hline & Basic Principles of Marxism & 3 & 48 & 3 \\
\hline & $\begin{array}{l}\text { Maoism and the Theoretical System } \\
\text { of Socialism }\end{array}$ & 6 & 96 & 4 \\
\hline & University Basic English (1) & 3 & 64 & 1 \\
\hline & University Basic English (2) & 3 & 64 & 2 \\
\hline & Sports (1) & 1 & 32 & 1 \\
\hline & Sports (2) & 1 & 32 & 2 \\
\hline & Sports (3) & 1 & 32 & 3 \\
\hline & Sports (4) & 1 & 32 & 4 \\
\hline & Military Theory & 1 & 16 & 2 \\
\hline & Total scores and classes & 25 & 496 & \\
\hline \multirow{18}{*}{$\begin{array}{l}\text { Professional } \\
\text { basic course }\end{array}$} & Inorganic and Analytical Chemistry & 3 & 48 & 1 \\
\hline & Programming Foundation $(\mathrm{C}++)$ & 3 & 48 & 1 \\
\hline & Linear Algebra & 3 & 48 & 1 \\
\hline & Advanced Mathematics (1) & 4 & 64 & 1 \\
\hline & Sketch & 3 & 48 & 2 \\
\hline & $\begin{array}{l}\text { Geometric Drawing and Shadow } \\
\text { Perspective }\end{array}$ & 2 & 32 & 2 \\
\hline & Organic Chemistry & 4 & 64 & 2 \\
\hline & Advanced Mathematics (2) & 4 & 64 & 2 \\
\hline & Probability and Statistics & 3 & 48 & 2 \\
\hline & University Physics & 4 & 64 & 2 \\
\hline & Botany & 3 & 48 & 2 \\
\hline & Graphic Design & 2 & 32 & 3 \\
\hline & Ecology & 2 & 32 & 3 \\
\hline & Color & 3 & 48 & 3 \\
\hline & Surveying & 3 & 48 & 3 \\
\hline & Garden Drawing & 3 & 48 & 3 \\
\hline & Garden History & 2 & 32 & 4 \\
\hline & Preliminary Design & 2 & 32 & 4 \\
\hline
\end{tabular}




\begin{tabular}{|c|c|c|c|c|}
\hline \multirow{10}{*}{$\begin{array}{l}\text { Professional } \\
\text { course }\end{array}$} & Model Design & 2 & 32 & 4 \\
\hline & Principle of Urban Planning & 2 & 32 & 5 \\
\hline & Plant Physiology & 2 & 32 & 5 \\
\hline & Total Scores & 59 & 944 & \\
\hline & Landscape and Art & 3 & 48 & 3 \\
\hline & Landscape Dendrology & 3 & 48 & 4 \\
\hline & Floriculture & 3 & 48 & 4 \\
\hline & Landscape Planning and Design & 3 & 48 & 5 \\
\hline & Garden Building & 3 & 48 & 6 \\
\hline & Landscape Engineering & 3 & 48 & 7 \\
\hline \multirow{12}{*}{$\begin{array}{l}\text { Experimental } \\
\text { course }\end{array}$} & Total scores & 18 & 288 & \\
\hline & $\begin{array}{l}\text { Inorganic and Analytical Chemistry } \\
\text { Experiment }\end{array}$ & 2 & 64 & 1 \\
\hline & Organic Chemistry Experiment & 2 & 64 & 2 \\
\hline & Botany Experiment & 2 & 32 & 2 \\
\hline & Computer Aided Design (CAD) & 2 & 32 & 3 \\
\hline & Landscape Ecology Experiment & 3 & 48 & 5 \\
\hline & Landscape Plant Experiment & 3 & 48 & 5 \\
\hline & Garden Building Construction & 2 & 32 & 5 \\
\hline & Plant Physiology Experiment & 2 & 32 & 5 \\
\hline & Landscape Plant Configuration & 2 & 32 & 6 \\
\hline & Landscape Planning and Design & 3 & 48 & 6 \\
\hline & Total scores & 23 & 432 & \\
\hline \multirow{4}{*}{$\begin{array}{l}\text { Practical } \\
\text { course }\end{array}$} & Landscape Project Management & 3 & 48 & 2 \\
\hline & Landscape Sketch & 3 & 102 & 5 \\
\hline & Professional Investigation and Report & 3 & 48 & 6 \\
\hline & Total scores & 9 & 198 & \\
\hline
\end{tabular}

\subsection{Training Objectives of LA}

The gap in LA majors is relatively large among Chinese universities due to different development history, academic foundation, and teachers structure of the university. As some experts have said that "landscape architects should have a solid theoretical foundation, rich academic background, and strong landscape expression techniques", which is more difficult to achieve this training objective of LA in all colleges and universities at this stage. Therefore, the training objectives should be clear based on different levels of colleges and universities, the same is true for North American (Jin \& Jian, 2011; Liu et al., 2011). To this end, the training objectives of Chinese LA can be divided into the following levels depend on the type, level, positioning and discipline basis of training units, and combined with Binyi Liu's suggestion for the structure and training objectives of LA professional education.

For the key universities with early LA majors, it is possible to cultivate a master's and doctoral talents with solid theoretical foundations and to understand the academic frontiers, and to strengthen the research team in this field. The aim is to maintain the sustainability of 
the LA discipline;

To meet the professional needs of civil servants for the LA and the forestry sector, some universities should cultivate comprehensive talents with landscape ecology foundation, urban planning theory and artistic aesthetics, and should focus on undergraduate and master's talents.

To meet the needs of the landscape architecture market in the process of China's economic development, some schools should train professional talents with practical ability for the institutes of landscape planning and design, landscape architecture companies, and environmental art companies. This includes junior college, undergraduate, master's and doctoral engineering in LA.

To meet the improvement of special skills for LA teachers and staff of LA companies, some universities should often hold academic forums, seminars, and practical design training, etc.

\subsection{Teching Staff of LA}

In response to the challenge of urbanization to resources, environment and space for human needs, and international competition, the teaching staff of LA worked in universities should have solid theoretical knowledge and practical operational skills. In order to achieve these goals, we should first strengthen international academic exchanges so that the teaching staff can keep abreast of the latest academic developments. At the same time, we can learn from advanced teaching models and integrate the excellent educational concepts of the East and West. Some of China's key universities which have established LA major earlier, have strengthened academic exchanges with Harvard University, Yale University, University of Pennsylvania, and Georgia University, and have selected young teachers for academic visiting each year. In addition, LA teachers should also actively participate in landscape planning and design projects, which make them more aware of the new situation and new problems encountered in LA, and to help solve these problems.

\section{Acknowledgements:}

This work was supported by teaching reform project of Jiangxi Normal University (No. JXSDJG1812). The English Curriculum Design and Effect Evaluation based on the Global Vision: Evidence from the Urban Ecology Course.

\section{Reference:}

ASLA. (2018). What Is Landscape Architecture? Retrieved from https://www.asla.org /aboutlandscapearchitecture.aspx

Chen, J. (2011). New life of landscape architecture-congratulation to its being approved as national first-level discipline. Journal of Chinese Landscape Architecture, 27(05), 9-10.

Jia, L., \& Qiu, J. (2008). The connotation of landscape architecture. World Architecture, 01, 98-100.

Jin, Y., \&Jian, S. (2011). Curriculum in the department of landscape architecture at the 
University Pennsylvania. Journal of Chinese Landscape Architecture, 27(02), 6-11.

$\mathrm{Li}$, B. (2007). Considering the direction of landscape architecture in contemporary China: The art of survival. Urban Space Design, 03, 19-21.

$\mathrm{Li}, \mathrm{J}$. (2002). The content and its forming process of modern landscape architecture. Journal of Chinese Landscape Architecture, 04, 4-7.

Li, Z., \& Qin, Y. (1994). An Overview of American Landscape Architecture School Education and Its Impact on China. Time Architecture, (04), 54-56, 37.

Lin, Y. (2003). Preliminary study of landscape architecture-small scale landscape architecture design in high density old city. Journal of Chang-an University (Architecture and Environment Science Edition), 04, 34-37.

Liu, J. (2005). The current situation and development prospects of Chinese landscape architecture. Guangdong Landscape Architecture, 02, 3-5.

Liu, J., Wang, B., \& Li, J. (2004). Opinion of "landscape architecture in terms of the wholeness of land". Journal of Chinese Landscape Architecture, 07, 51-54.

Liu, Y., Li, Z., \& Wang, H. (2011). A study of education features in the undergraduate program of landscape architecture in the University of Georgia. Journal of Chinese Landscape Architecture, 27(02), 12-16.

Sun, X. (2002). Landscape architecture from garden craft, garden art, landscape gardening to landscape architecture, earthscape planning. Journal of Chinese Landscape Architecture, 04, 8-13.

Wang, X. (1999). Landscape Architecture is 'Jiangguan/Fengjing Jianzhu'?. Journal of Chinese Landscape Architecture, 06, 46-48.

$\mathrm{Yu}, \mathrm{K}$. (2004). Landscape architecture in terms of the wholeness of land. Journal of Chinese Landscape Architecture, 07, 47-51.

Yu, K., \& Liu, D. (1999). American landscape architecture. Urban Planning Overseas, 02, $1-9,43$.

Zhang, Q. (2011). Thinking of the construction of the first level discipline landscape architecture. Journal of Chinese Landscape Architecture, 27(05), 16-17.

Zhang, R. (2007). Landscape Architecture: Rebuilding Harmonious Taoyuan and Spiritual Homeland. China Engineering and Consulting, 03, 10-11.

\section{Copyright Disclaimer}

Copyright reserved by the authors.

This article is an open-access article distributed under the terms and conditions of the Creative Commons Attribution license (http://creativecommons.org/licenses/by/3.0/). 